\title{
ARTICLE
}

\section{Radiation Detection by Liquid Phase Epitaxially Grown InSb Detector}

\author{
Ikuo KANNO $^{1 *}$, Yasunari MORITA ${ }^{1}$, Yuki SATO ${ }^{1}$, \\ Atsushi BIRUMACHI ${ }^{2}$, Tatsuya NAKAMURA ${ }^{2}$, and Masaki KATAGIRI ${ }^{2}$ \\ ${ }^{1}$ Kyoto University, Yoshidahon-machi, Sakyo,Kyoto 606-8501, Japan \\ ${ }^{2}$ Japan Atomic Energy Agency, Tokai, Naka, Ibaraki 319-1195, Japan
}

\begin{abstract}
A radiation detector was fabricated with an epitaxially grown InSb crystal. The resistivity of the epitaxial crystal was 1.5 orders of magnitude higher than that of substrate crystal, on the other hand, the Hall mobility was smaller. The resistance of the InSb detector showed highest value among the previously fabricated ones. Pulses induced by alpha particles were observed, however, proper energy spectrum was not obtained, due to the poor charge collection brought by the small Hall mobility.
\end{abstract}

KEYWORDS: radiation detector, InSb, alpha particles, epitaxial crystal growth

\section{Introduction}

For the detection of poisonous elements in industrial products, X-ray fluorescence spectroscopy (XFS) is a commonly employed method. In the XFS measurement system, photon detector made of $\mathrm{Si}$ is widely installed. The detectable range of elements using XFS is from $\mathrm{Na}$ to $\mathrm{Pb}$. In the measurement of elements with smaller atomic number than $\mathrm{Na}$, the K-X rays with the energy below $100 \mathrm{eV}$ are hard to be separated from electronic noise due to the energy resolution of Si detector. On the other hand, the energy of $\mathrm{K}-\mathrm{X}$ rays with high atomic number elements than $\mathrm{Pb}$ is greater than $80 \mathrm{keV}$. With the small atomic number and density of $\mathrm{Si}$, the absorption efficiency is too small to measure the $\mathrm{K}-\mathrm{X}$ rays with good statistics in a restricted time.

A compound semiconductor InSb can be a substrate of photon detectors to make a breakthrough of the situation described above. ${ }^{1)}$ Due to the high $\mathrm{Z}$ numbers and high density of InSb, the photon absorption efficiency is 400-1000 times higher than that of $\mathrm{Si}$. The expected energy resolution of $\mathrm{InSb}$ detector is twice that of Si detector, because the band gap energy of $\mathrm{InSb}$ is $1 / 6$ of that of Si.

The authors have been developing InSb radiation detectors. With commercial p-type InSb substrates, pn junction detectors and Schottky detectors were fabricated. ${ }^{2,3)}$ Also, Schottky detectors were made with undoped-type InSb substrates. ${ }^{4)}$ Due to the low resistivity of commercial $\mathrm{InSb}$ substrates, large noise appeared when bias voltage was applied: radiation detection was carried out without applying bias voltage in most cases. The estimated depletion layer thickness without applying bias voltage was some $\mu \mathrm{m}$ : alpha particles with 5.5 MeV penetrated the depletion layer. The pulses due to the alpha particles were observed at the temperature from 2 to $115 \mathrm{~K}^{2}{ }^{2}$ As an application of $\mathrm{InSb}$ detector, thermal neutrons were detected with the nuclear reaction of $\mathrm{n}+{ }^{3} \mathrm{He} \rightarrow \mathrm{p}+\mathrm{t}^{5,6}$ ) When the InSb detector was employed in the detection of gamma rays emitted from ${ }^{133} \mathrm{Ba}, 81 \mathrm{keV}$ in energy, large escape peak was clearly seen

*Corresponding Author, E-mail:kanno@nucleng.kyoto-u.ac.jp (C) Atomic Energy Society of Japan with a very small photo-peak. ${ }^{7,8)}$

In this paper, the first result of detecting alpha particles by a detector made of epitaxial InSb is described.

\section{Experiments}

\section{Liquid Phase Epitaxial InSb Crystal Growth}

As a substrate crystal, n-type InSb wafer with the diameter and thickness of 2 inches and $0.4 \mathrm{~mm}$, and crystallographic orientation (100) was used (Galaxy Compound Semiconductor, Inc., U.S.A.). After cleaning the surfaces, the InSb wafer was placed in a wafer boat made of high purity carbon. Nearly $50 \mathrm{~g}$ of $\mathrm{In}-\mathrm{Sb}(\sim 20 \%$ in weight) was filled in a source boat as shown in Fig. 1. The

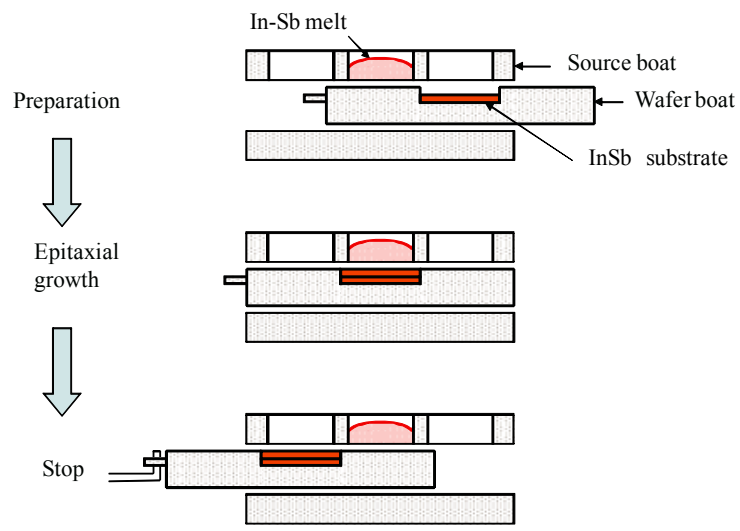

Fig. 1 Schematic drawing of liquid phase epitaxial crystal growth.

mixture of In-Sb was melt by an electric heater and kept at $700{ }^{\circ} \mathrm{C}$ for three hours in $\mathrm{H}_{2}$ atmosphere to remove oxides in the raw materials. The temperature of the In-Sb melt was set at $450{ }^{\circ} \mathrm{C}$ for one hour. The temperature of the In-Sb melt was set to decrease $0.2{ }^{\circ} \mathrm{C} / \mathrm{min}$. At the starting temperature of growing epitaxial crystal, $415{ }^{\circ} \mathrm{C}$, the wafer boat was moved to meet with In-Sb melt. After 40 min., the wafer boat was removed from the melt, and the epitaxial growth process was over. The obtained thickness of the epitaxial InSb crystal was measured by a microscope and was $97 \mu \mathrm{m}$. 

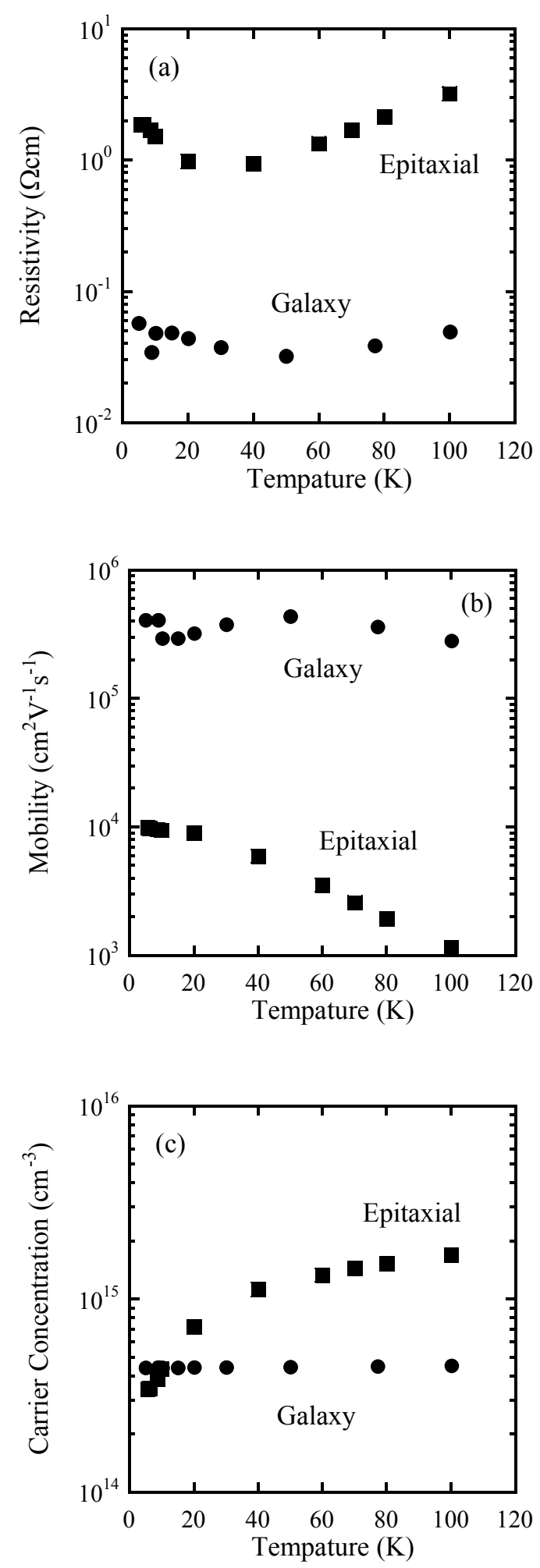

Fig. 2 The electric properties of epitaxially grown $\mathrm{InSb}$ crystal, (a) resistivity, (b) Hall mobility and (c) carrier concentration. "Galaxy" shows the ones of a substrate crystal.

\section{Hall Measurement of Epitaxial InSb Crystal}

The epitaxial InSb crystal was grown on a substrate $\mathrm{InSb}$ wafer, which resistivity was $5.7 \times 10^{-2} \Omega \mathrm{cm}$ at $5 \mathrm{~K}$. For the measurement of the resistivity of epitaxially grown crystal, which resistivity supposed to be higher than the substrate crystal, the substrate InSb wafer had to be removed by lapping.

The epitaxial $\mathrm{InSb}$ crystal was attached on a $\mathrm{BN}$ chip (nearly $1 \mathrm{~cm} \times 1 \mathrm{~cm} \times 2 \mathrm{~mm}$ in thickness), with epitaxial side facing with the $\mathrm{BN}$ chip. The substrate InSb crystal was lapped with diamond slurry with the diameter of diamond 9 $\mu \mathrm{m}$ for rough lapping. For the finishing lap, $3 \mu \mathrm{m}$ diameter diamond slurry was used. The thickness of the InSb crystal was occasionally measured by a height meter.

The BN chip with a lapped epitaxial InSb crystal was placed on a sample holder of a cryostat. Four gold wires were In soldered to the corners of the epitaxial InSb crystal and were connected to the electrodes on the sample holder.

The cryostat was placed between the yoke of an electric magnet. The epitaxial InSb crystal was cooled by the flow of liquid He.

The resistivity, Hall mobility and carrier concentration are shown in Fig. 2 (a) (c). For comparison, those of the substrate crystal are plotted in the figures.

\section{Detector Fabrication}

With epitaxial InSb chips other than the one used for Hall measurement, but taken from the same epitaxially grown InSb wafer, radiation detectors were fabricated. After cleaning both the epitaxial and substrate surfaces, an electrode region with the diameter of $0.5 \mathrm{~mm}$ was defined using photo-resist. The substrate surface was attached to a $\mathrm{Cu}$ plate with In solder and resulted in an Ohmic contact. The epitaxial $\mathrm{InSb}$ chip on a $\mathrm{Cu}$ plate was placed in a vacuum chamber for depositing gold with evaporation to have rectifying contacts.

Current-voltage $(I-V)$ characteristic was measured between the rectifying and the Ohmic contacts. Typical $I-V$ curve measured at $4.2 \mathrm{~K}$ is shown in Fig. 3. The resistivity as a diode at $4.2 \mathrm{~K}$ was $570 \mathrm{k} \Omega$.

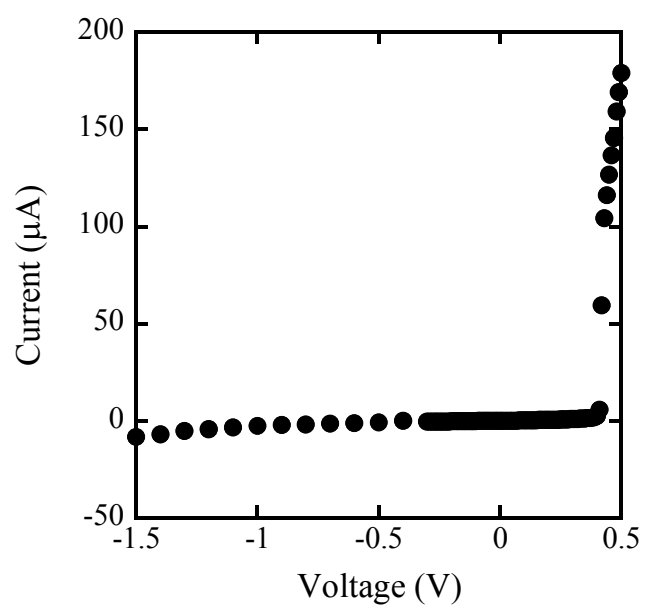

Fig. 3 Typical current-voltage curve of radiation detectors made of epitaxial InSb crystal. 


\section{Radiation Measurements}

Fabricated epitaxial InSb detector was mounted on a $0.3 \mathrm{~K}$ stage of a cryostat (Infrared Co., U.S.A.). Facing with the detector, ${ }^{241} \mathrm{Am}$ source was placed. The output pulses of the detector were amplified by a preamplifier (Canberra 2003) and a main amplifier (Canberra 2021). Both preamplifier and amplifier outputs were observed by a digital storage oscilloscope. Measurements were carried out without applying bias voltage. Typical amplifier output obtained at $4.2 \mathrm{~K}$ is shown in Fig. 4.

Table 1 Summary of InSb detector resistances. SB: surface barrier, pn: $p n$ junction, W.T.: Wafer Technology, England, S.E.I.: Sumitomo Electric Corp., Japan, Nitric+Lactic: mixture of nitric and lactic acids. HF mixture: mixture of $\mathrm{HF}$ (1), $\mathrm{H}_{2} \mathrm{O}$ (3) and $\mathrm{H}_{2} \mathrm{O}_{2}$ (1). Mesa: electrode was made on a mesa with $10 \mu \mathrm{m}$ height. Resist: electrode was defined by photo-resist.

\begin{tabular}{|c|c|c|c|c|c|c|}
\hline $\begin{array}{c}\text { Junction } \\
\text { Type } \\
\end{array}$ & \begin{tabular}{|c} 
Conducting \\
Type
\end{tabular} & Supplier & Etchant & Electrode & Metal & \begin{tabular}{|c} 
Resistance \\
$(\mathrm{k} \Omega)$
\end{tabular} \\
\hline $\mathrm{SB}$ & $y^{2}$ & W.T. & Nitric+Lactic & $\begin{array}{c}3 \mathrm{~mm} \text { dia. } \\
10 \mu \mathrm{m} \text { mesa }\end{array}$ & \begin{tabular}{|c|}
$\mathrm{Au}-\mathrm{Pd}(40 \%)$ \\
$5 \mathrm{~nm}$ \\
\end{tabular} & 50 \\
\hline $\mathrm{SB}$ & undoped & S.E.I. & Nitric +Lactic & $\begin{array}{l}3 \mathrm{~mm} \text { dia } \\
10 \mathrm{um} \text { mesa }\end{array}$ & $\begin{array}{c}\mathrm{Au}-\mathrm{Pd}(40 \%) \\
5 \mathrm{~nm} \\
\end{array}$ & 16 \\
\hline SB & undoped & S.E.I. & Nitric +Lactic & $\begin{array}{l}1.5 \mathrm{~mm} \text { dia. } \\
10 u \mathrm{~m} \text { mesa }\end{array}$ & $\begin{array}{c}\mathrm{Au}-\mathrm{Pd}(40 \%) \\
5 \mathrm{~nm}\end{array}$ & 4.6 \\
\hline SB & undoped & W.T. & $\mathrm{Br}$ methanol & $\begin{array}{c}1 \mathrm{~mm} \text { dia. } \\
\text { Resist }\end{array}$ & $\mathrm{Au} 20 \mathrm{~nm}$ & 3.5 \\
\hline SB & undoped & W.T. & HF mixture & $\begin{array}{c}1 \text { mm dia. } \\
\text { Resist }\end{array}$ & $\begin{array}{c}\mathrm{Au}-\mathrm{Pd}(40 \%) \\
12 \mathrm{~nm}\end{array}$ & 4.4 \\
\hline pn & $\mathrm{p}$ & W.T. & Nitric + Lactic & $\begin{array}{c}3 \mathrm{~mm} \text { dia } \\
10 \mu \mathrm{m} \text { mesa }\end{array}$ & $\begin{array}{c}\text { Sn } 5 \mathrm{~nm}, \\
\mathrm{Al} 0.1 \mathrm{um}\end{array}$ & 250 \\
\hline
\end{tabular}

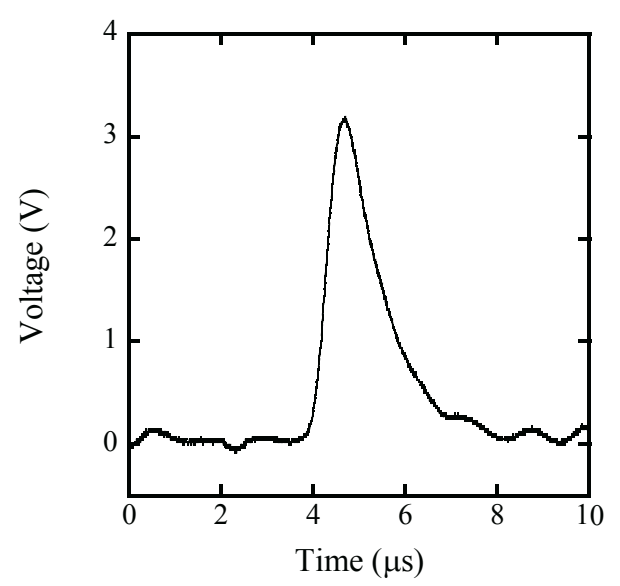

Fig. 4 Typical pulse of main amplifier output.

\section{Results}

\section{Electric Properties of Epitaxial InSb Crystal}

The resistivity of the epitaxial InSb was nearly 1.5 orders of magnitude higher than the one of substrate InSb crystal. If we see the data points measured below $10 \mathrm{~K}$, the carrier concentrations were nearly the same for both epitaxial and substrate InSb. On the other hand, Hall mobility of epitaxial InSb was 1.5 orders of magnitude smaller than substrate InSb. This indicates that the high resistivity of epitaxial $\mathrm{InSb}$ was brought in by the incomplete crystallity, which at the same time resulted in poor Hall mobility. The epitaxial crystal growth at lower temperature would result in better crystallity. At the same time, smaller impurity concentration would be obtained and would bring less temperature dependence of the electric properties.

\section{Current-voltage Curve of InSb Detector}

The resistances of previously fabricated $\mathrm{InSb}$ detectors are shown in Table 1. The highest resistance in InSb detector fabricated in the past was the one with $p n$-junction, $250 \mathrm{k} \Omega$. The resistance obtained by surface barrier detector was smaller by one order of magnitude. On the other hand, the resistance of epitaxial InSb surface barrier detector showed $570 \mathrm{k} \Omega$ at $5 \mathrm{~K}$. This resistance is very high compared with previously fabricated InSb detectors. The epitaxial InSb crystal looks very promising as a substrate of radiation detectors.

\section{Alpha Particle Pulses}

Pulses induced by alpha particles were observed as shown in Fig. 4. The energy spectrum of alpha particles, however, did not show very clear peak. The deteriorated energy spectrum might be the result of poor Hall mobility: electrons and holes were captured by impurities or crystal defects due to the small mobilities and a weak electric field strength.

\section{Conclusion}

A radiation detector was fabricated with epitaxial $\mathrm{InSb}$ crystal for the first time. The resistance of the detector showed highest value among the previously fabricated ones. Due to the small Hall mobility, incomplete charge collection was taken place. With an improved growth technique, epitaxial InSb crystal can be a promising substrate for radiation detectors.

\section{Acknowledgment}

This work was carried out as a project of New Energy Development Organization (0827002).

\section{References}

1) Wm. C. McHarris, "InSb as a $\gamma$-ray detector", Nucl. Instrum. Methods in Phys. Res., A242, 373 (1986).

2) I. Kanno, F. Yoshihara, R. Nouchi, O. Sugiura, Y. Murase, T. Nakamura, M. Katagiri, "Radiation measurements by a cryogenic $p n$ junction InSb detector with operating temperature up to 115 K”, Rev. Sci. Instrum., 74, 3968 (2003).

3) I. Kanno, S. Hishiki, H. Murakami, O. Sugiura, Y. Murase, T. Nakamura, M. Katagiri, "Schottky and $p n$ junction cryogenic radiation detectors made of $p$-InSb compound semiconductor", Nucl. Instrum. Methods in Phys. Res., A520, 93 (2004).

4) I. Kanno, S Hishiki, O. Sugiura, R. Xiang, T. Nakamura, M. Katagiri, "Photon detection by a ccryogenic InSb detector", Rev. Sci. Instrum., 76, 023102 (2005).

5) T. Nakamura, M. Katagiri, Y. Aratono, I. Kanno, S. Hishiki, O. Sugiura, Y. Murase, "Cryogenic neutron detector comprising an InSb semiconductor detector and a supercritical helium-3 gas converter", Rev. Sci. Instrum., 75, 340 (2004).

6) T. Nakamura, M. Katagiri, Y. Aratono, I. Kanno, S. Hishiki, O. Sugiura, Y. Murase, "Cryogenic neutron detector by $\mathrm{InSb}$ 
semiconductor detector with high-density helium-3 gas converter", Nucl. Instrum. Methods in Phys. Res., A520, 76 (2004).

7) S. Hishiki, I. Kanno, O. Sugiura, R. Xiang, T. Nakamura, M. Katagiri, "Undoped InSb schottky detector for gamma ray measurements", IEEE Trans. Nucl. Sci., 52, 3172 (2005).

8) S. Hishiki, Y. Kogetsu, I. Kanno, T. Nakamura, M. Katagiri, "First detection of gamma ray peaks by an undoped InSb Schottky detector", Nucl. Instrum. Methods in Phys. Res., A559, 558 (2006). 